\title{
New curriculum standard, new concept, new pattern - Thinking and practice about construction of science museum in primary schools
}

\author{
Zhenqiang Wang ${ }^{1, *}$, and Mingna Jia ${ }^{2}$ \\ 1 Primary School of Nanjing Xiaozhuang University, Nanjing, China, Nanjing, Jiangsu 210097, China \\ 2 Jiangning Guli Central Primary School, Nanjing, China, Nanjing, Jiangsu 211100, China \\ *Corresponding Author: 63112981@163.com
}

(Received: 05/24/2021; Accepted: 12/14/2021; Published: 12/18/2021)

DOI: https://doi.org/10.37906/real.2021.7

\begin{abstract}
Why build a "Science Museum" in primary school? How to develop and implement "Science Museum" project? In this paper, the practice of Group of Xiao Xiao Science and Engineering in the Science Museum of Primary School Attached to Nanjing Xiaozhuang University is used as an example for demonstration. The Science Museum introduces learning new curriculum standard, putting the new concept into practice, promoting the integration of the science and technology activities and science courses. At the same time, this paper also discusses how to develop the curriculum by relying on the Group of Xiao Xiao Science and Engineering.
\end{abstract}

Keywords: School Science Museum; Group of Xiao Xiao Science and Engineering; New curriculum standard; Concept; Pattern.

\section{Introduction}

On September 13, 2017, China put forward the six core qualities for Chinese students to develop, including humanistic details, scientific spirit, learning to study, healthy life, responsibility, practice and innovation, to promote the all-round development of our students (Research Group on core literacy, 2017). In 2017, the Ministry of Education promulgated the Compulsory Education (The new curriculum standard"). In the fourth part of the curriculum resources development and utilization suggestions that: (a) Construction of Science Laboratory; (b) Development and construction of campus resources; (c) Development and construction of off-campus resources; (d) Development and application of network resources.

In 2008, when I was a volunteer in Zhengzhou Science and Technology Museum, I realized that the Science Museum is important for primary and middle school students. In November 2015, Primary School Attached to Nanjing Xiaozhuang University (abbreviated as "NJXZFX") became the first school in Nanjing to have established the Science Museum in school, and carried out practical exploration. Science in Primary School is a basic course, a practical course and a comprehensive composition. "New Curriculum Standard" puts forward the education idea of "observation", "investigation", "comparison", "classification", "analysis of data", and so on (China, 2017). Relying on the Science Museum, we have developed the project "Group of Xiao Xiao Science and Engineering", which opened up the science and technology practice teaching area and established the connection between the science and technology activities and the science curriculum. The Science Museum tries to combine the science and technology activities with the Science Curriculum, and explores the project-based learning model of the Group of Xiao Xiao Science and Engineering 


\section{The necessity of linking up "the curriculum standard"}

The Science Museum is an institution for the education and dissemination of popular science. Since the 1980s, we have paid attention to the cultivation of scientific epistemology, methodology and values (Zhu, 2017). At the end of 2015, the NJXZFX Science Museum was opened. Here, we evaluate the issue on how to play the benefits, how to carry out maintenance and management, how to evaluation, and so on.

In China, the outline of the National Action Plan for Scientific Literacy (2010-2020) promulgated by the State Council requires the Science and Technology Museum to "play the role of popular science education." "The resources of Science and Technology Museum must be combined with the implementation of school science curriculum, comprehensive practical activities and research-based learning." The combination of Science and Technology Museum resources and school science curriculum is the way to meet the science curriculum standard of primary school, and the integrated practical activities and research learning are also required by the curriculum standard of primary school. At present, most primary school science teachers' biggest demand for "Science Museum in school" is to help science teaching. Although the "new curriculum standard" has stipulated the teaching content and educational objective, many primary schools lack the necessary teaching resources and teachers to meet this requirement. If the Science Museum can be connected with the "new curriculum standard" and provide these teaching resources and teachers for the school, the Science Museum Construction Project of the school will have a new impetus for development.

NJXZFX has put forward clear requirements for schools to carry out science and technology practice activities. Primary school students from grade 1-2 are required to visit the Science Museum for 2 class periods every year, and those from grade 3-5 are required to visit the Science Museum 4 class periods. The sixth-grade students carry out the research study curriculum of the Science Museum during each school year for 8-10 class periods. Through the combination of "Science Class" and "Science Museum", we carry out the teaching practice of the "new curriculum standard" of science in primary schools, and show how this can make up for school science education time, space shortage.

More than two years of practice has made me realize that using the resources of the Science Experience Center to connect the "new curriculum standards" of elementary school science can not only play the role of science education and science popularization in the Science Experience Center, but also stimulate students' enthusiasm for learning science.

\section{Study the "Curriculum Standard" and explore the new model}

In 2015, a research report on the exhibit-based Science Education Project of "Science Museum activities on campus" by the topic group of the Science and Technology Museum Committee of the National Museum of Natural Science pointed out that although most Science and Technology museums carry out the project of library-school integration, the contents and methods of activities are too simple and superficial, and most of them organize school groups to visit the Science and Technology museums or send the exhibits of "Mobile Science Museums" to schools. The Science and Technology Museum seldom combines the teaching objectives and contents of different grades in the "new curriculum standard" issued by the Ministry of Education, and designs the "menu" of targeted educational activities for students. Schools and students will visit the Science Museum during the spring or autumn school trip, exploring the nature (Research Group of Science and Technology Museum, National Museum of Natural Science, 2015). As the object of this study, the real value of the collection or exhibits is not its material, shape, technology, performance itself, but it bears witness to the natural and human social life of information. Information about the life of nature and human society in specific times, processes, environments, and conditions is recorded in various forms in collections/exhibits. In this sense, the 
collection/exhibit is a carrier of information and serves as a witness of natural and human social life, with research and educational/dissemination value (Wang \& Zhu, 1998). In the 2010 survey, only about twothirds of science museums around the world have conducted educational activities. According to the 2010 survey, three quarters of science museums are engaged in educational activities. That's an improvement than 2010. According to the 2014 survey data, science performances, laboratories and science and technology competitions account for more than 40 percent of the activities held by local science museums, while the proportion of educational activities or project-based learning based on exhibits is low (Research Group of Science and Technology Museum, National Museum of Natural Science, 2015). "Carrying out the new concept" is to carry out the "new curriculum standard" and the advanced idea of science museum education, and to abandon the old "museum-school combination" model, which mainly organizes students to "take a cursory and fancy tour", adopt the new mode of "comprehensive practice activity and research study".

\subsection{The educational concept of "new curriculum standard"}

The course of "research learning in Science Experience Library" meets the needs of schools and teachers, not only in teaching resources and teachers, but also in teaching ideas. By studying the "new curriculum standard", we find that the word "inquiry" appears 164 times in the "new curriculum standard". The national standards for Science Education published by the United States in 1996 advocates "science education with inquiry as its core", and the ideas of STEM education in the 2011 K-12 science education framework, and the 2013 national standards for the next generation of science education, developed as an "interdisciplinary project-based learning based on science and engineering practice". These important educational concepts apply not only to formal science education in schools but also to non-formal science education $(\mathrm{Zhu}, 2017)$. The science curriculum in primary schools advocates for a variety of project-based learning styles. In the course of "research-based learning in Science Experience Library", we should not only reflect students' inquiry learning, but also the integration of science, technology, engineering and mathematics. Through practice, students put forward questions, analyze problems, explore problems, and solve problems. We should attach importance to students' thinking in practice and cultivate their ability to analyze and solve problems.

\subsection{The combination of exhibition and teaching and the practice of the new concept}

What kind of teaching model can carry out the new educational concept? "The new curriculum standard" points out that it should be by means of "observation, investigation, comparison, classification, analysis of data, and drawing conclusions" (Wu, 1999). In inquiry teaching, we should cultivate students' creative thinking ability, enhance their understanding of scientific inquiry and improve their practical skills. Xiao Xiao Science and Engineering Group as the practice base of Science Education. The site, Exhibition Hall and exhibits of are equivalent to classrooms and teaching aids of the school, and the program of science and technology practice activities is equivalent to school-based teaching materials. Exhibits cannot fully achieve its function of science and technology education alone, but also to develop and carry out a large number of scientific and technological practice. First, the students were asked to visit and experience the exhibits of the Science Museum, and then put forward questions, analyze problems, explore problems and solve problems in the light of these exhibits, so that they can use scientific and technical knowledge to improve the ability to deal with practical problems, participate in public affairs, and serve other people and social values. When a student encounters a problem in a real situation, they need to propose a general process for solving the problem. One example of such problem would be how to raise high-quality silkworm. It is divided into the following sections: (a) Guiding students to observe and find the problems they encounter in life, which can be extended from study, life and science; (b) For these problems, select some of their own can study the problem, a group discussion exchange to develop the possibility of research, which also serves as a preliminary survey. It is necessary 
to consult classmates, parents, some books; (c) Select the problem to be studied, make a preliminary research plan, research methods to be used, here mainly guide students to use questionnaire survey and interview, field research methods; (d) Write questionnaire, interview outline for pre-test, then modify it according to the test situation; (e) Develop a questionnaire for distribution; (f) Develop a statistical questionnaire, analyze and write scientific papers to put forward the feasibility of proposals; $(\mathrm{g})$ Share research findings.

\subsection{Project of science and technology practice course of scientific planning}

How to give prominence to its own characteristics and give full play to its educational function? Science classes in schools are limited by time and space. NJXZFX spared no expense in reducing the space of the science preparation room and built the "Science Museum", which includes six exhibition areas: Preface Hall; Electromagnetic Mystery; Sound, Light Art, Sports Melody; Digital Technology Exhibition area; Health and Safety Exhibition area; and Virtual Laboratory, with a total of 32 different exhibition items. Combined with the school's Science and Technology Festival activities, activities are designed around different themes such as the "force", "sound", "heat", "electricity" and "light". The School Science Experience Hall, maker classroom, the classroom of the future (robot classroom) are combined together. During the experience visit, students can find problems, combined with life, hands-on design and production, programming control.

Relying on Xiao Xiao Science and Engineering Group, the school tries to combine "science" curriculum with "life", develop "experience maker" curriculum, promote "Xiao Xiao Science and engineering group project learning method", and promote the cultivation of students' innovative skills.

\section{4. "Xiao Xiao Science and Engineering Group" promotes the integration of Science Museum and Science Curriculum}

In China, many scholars have made a profound interpretation of "learning by doing": the core of "learning by doing" is actually "direct experience" of "indirect experience" (Tao Xing Zhi Education Research Association of Jiangsu Province \& Tao Xin Zhi Research Office, Xiaozhuang Normal University, Nanjing, 1981).

Xiao Xiao Science and Engineering Group is a continuation of Tao Xing Zhi founded in 1928 Xiaozhuang village self-defense group. Tao Xing Zhi put forward the style of work and study group, work to health, study to Ming Sheng, Tuan to health (Tao Xing Zhi Education Research Association of Jiangsu Province \& Tao Xing Zhi Research Office, Xiaozhuang Normal University, Nanjing, 1981). In the new era, the meaning given to the group is: work is practice; study is learning; group is collective "work" that is guided by the spirit of craftsmen, with thinking and practice. "Learning" represents learning and application of knowledge in real and complex situations. "Tuan" encompasses two dimensions: one is the "thing" on the elaboration: in life learning knowledge comprehensive application, cross-border integration; the other is on "people": students and students, students and teachers, students and experts, students and parents and other individuals.

This project combines all the needs in the development of the new era of talent training: to empower the students, develop their skills, stimulate motivation, the knowledge learned in real problems to be applied to solve real life problems, to achieve the change of others and the value of life in the service of social teaching activities, and to form wisdom. With the support of Xiao Xiao science and Engineering Group, the combination of Science Museum and science curriculum are greatly supported, along with the group activities to improve students' scientific literacy.

4.1. Research and development of new curriculum

REAL 2021, 6(2)

https://doi.org/10.37906/real.2021.7 
4.1.1. Combing the knowledge points and pointing to the teaching of big concept of science

The 14 teaching concepts of science emphasize that in science, every phenomenon has one or more causes. The explanations, theories, and models given by science are the ones that best fit the facts for a given period of time. The knowledge of scientific discoveries can be used to develop technologies and products for the benefit of mankind. The use of science often has ethical, social, economic and political influence.

The students in grade 3-6 in primary school are taught by Xiao Xiao Science and Engineering Group. The knowledge points are sorted out and pointed to the teaching of the big concept of science. The curriculum development originates from the student life, returns to the life. So far, "shadow play", "DIY film", "DIY Lights" and many more activities were developed. The new curriculum development pays attention to the student's inquiry practice and the experience, stimulates the student to participate in the inquiry with enthusiasm.

\subsubsection{Diversified curriculum development}

The length of science courses in Xiao Xiao Science and Engineering groups is different. And the characteristics of the courses vary with the students' age: the junior grade emphasizes on experience and popularization of science, the middle grade emphasizes on interest research, and the senior grade carries out (open) research study. The content of the course is drawn from the following three sources:

(a) School-based national curriculum. There are many practical courses in the science textbooks. Because of the limitation of the teaching staff, we can carry out educational activities in the Science Museum. For example, "the impact of acid rain on human beings" and "the impact of earthquakes on human beings" in the curriculum standard of primary schools can be simulated by the exhibits in the Science Museum to experience the feelings and gain direct experience.

(b) Introductory course. The introduction of the Nanjing Branch of the Chinese Academy of Sciences to develop a curriculum suitable for the Science Museum, the adaptation of the school situation, can also rely on colleges and universities to carry out curriculum practice activities, so that students have access to knowledge and skills of the "direct experience", but also the original abstract "interdisciplinary concept" into the experience and practice of personal experience. The whole process of the project fully embodies the elements of "practice", "project-based learning", "interdisciplinary concept", "direct experience", which is a complete "interdisciplinary project-based learning based on science and Engineering Practice" process (Zhu, 2017). For example, our school applied for admission to the Belt and Road practice program at Southeast University in China. Classes includes projects such as make your own telescope and spice.

(c) Self-development. While the students experience different practical activities, the preparation of courses are made to be suitable for students. For example, the "Experience Maker" course was developed and won the National Top Ten Excellent Courses for New Education. It mainly introduces the mystery of magnetic levitation, decrypt the movie and so on.

At present, Xiao Xiao Small Science and Engineering Group has developed more than 20 science practice courses. Some courses are offered and developed in Table 1.

Table 1 introduction of some courses offered and developed by Xiao Xiao science and Engineering College

\begin{tabular}{lcc}
\hline Grade & Knowledge Points of docking science materials & Course \\
\hline K4-K6 & Mode of motion, Simple circuit, Magical energy & Remote-controlled robot \\
K3-K5 & Metals, Common materials, Force, Conductors and insulators & Electric fan
\end{tabular}

REAL 2021, 6(2) 
K3, K5 Plastics, the march of light, Refraction, Reflection Shadow play

K3-K5 Little scientist, Mode of motion, Simple machinery Revealing film

The curriculum of Xiao Xiao Science and Engineering group is centered on the science curriculum and advocates the STEWAM education method, which emphasizes the arts and embodies the scientific nature while carrying rich cultural information and embodying certain humanistic characteristics, contains the artistic sense, the cultural nature, the moral duty moves student's mind, with emphasis on "W" writing. Through the research, expression and communication of the project, we can solve the practical problems, record the changes of students' scientific thinking, and present the overall thinking, the thoroughness of the research process and the profundity of the research problems, which not only embodies the innovation, but also embodies the creativity and creation.

\subsection{Curriculum Implementation Path}

Relying on the Xiao Xiao Science and Engineering Group, the school aims to train students to apply the knowledge of combined learning into their daily life based on the process of students' questions, analysis, inquiry and problem-solving in real life, to serve humanity and to have an impact on society. The curriculums are implemented mainly from the following six aspects of student activities: Pulpit, Essay, Inventions, Investigate, Competition, Pleadings.

\subsubsection{Pulpit}

To explain the research results that have been carried out or have been obtained. The objective is to improve the scientific literacy of students and enhance their ability to participate in social and economic development. Pulpit mainly centers around the students in life to carry out a survey, inventions, and so on. At present, a survey has been carried out on fish farming in ponds, the placement of trash cans on campus, food and nutrition safety of students, and a survey of extra-curricular tutoring classes for primary school students.

\subsubsection{Essay}

A written summary of scientific observations, experiments, or investigations carried out in scientific activities. The students should know the basic scientific method, the essence of science, and set up the scientific thought. The topics of this paper include silkworm rearing, the elementary knowledge of fish farming, the comparison between hydroponic plants and soil-grown plants, the effect of light on eggs, the growth of baby nails, the secrets of steering wheel, the research of floor Tile anti-skid, etc.

\subsubsection{Inventions}

Using the existing scientific and technical knowledge and practical ability, students need to identify things in daily study, life, that are inconvenient or unsatisfactory, to improve and innovation, training creative ability, thinking ability. Every year in the Science and Technology Festival, students carry out waste to treasure, creative flowerpots, and small production projects.

\subsubsection{Investigate}

Combining study and life, we can make on-the-spot visit to the things we care about. Through observation, investigation and research, we can understand and make clear the real situation of the things, and stimulate our thinking. We train the students to know the basic scientific methods, understand the nature of science, and have the ability to use them to deal with practical problems and participate in public affairs. A survey has been carried out on the installation of baby safety seats in subway cars, suggestions on the distribution of leaflets at the gate of the school, a survey on the use of public bicycles, a survey on the use of public bicycles, a survey on the diet and health of primary schools attached to the 
school, a survey on the use of mobile phones by primary students, suggestions on the pick-up and dropoff of children by parents of primary schools attached to the school, and a survey on the use of science and technology museums in the school.

\subsubsection{Competition}

To encourage students to participate in activities, cultivate students' practical ability and innovative thinking ability, understand the impact of science and technology on society and individuals, and develop students' ability to find and solve problems, Science and Technology Festival includes activities such as: looking for life's science and technology, my anti-disease tips, paper airplanes, science fiction paintings, small production, small scientific research and other individual projects, as well as robot competition, building turnip towers and other collective projects, for students in different grades to arrange lectures from different topics expert in popular science (how to invent, innovative planting, animal science, human science and so on). In addition, students are encouraged to participate in various science and technology competitions organized by the provinces and cities, such as the Jiangsu Science and technology innovation competition, the Jiangsu inter-campus science and technology competition, the Nanjing Science and Technology Innovation Competition, the Nanjing five small competition and so on.

\subsubsection{Pleadings}

For their own research results or papers, we will explain and reply to the comprehensive evaluation of students, inspection, and select a small academician of science. This is to cultivate students to set up scientific ideas, advocate scientific spirit, and dare to open research results, accept questions, constantly update and conduct in-depth research. For example, for the graduating class of students, they need to choose their own topics, carry out research, and finally conduct defense activities.

\subsection{Promoting the "little mister" system}

There are 6 science teachers attached to Nanjing Xiaozhuang University, only 1 full-time staff. The full-time personnel shall manage the scientific preparation room, scientific teaching, participate in teaching and research, organize scientific and technological activities, etc. To maintain and manage the Science Museum, how can we solve this problem and motivate students to go to the Science Museum? I carry out the "little mister" system proposed by President Tao Xing Zhi. To train young students, we select excellent students from the entire school, employed as the staff of the Science Experience Museum. Each semester for the school to recruit 12 Science and Technology Museum staff, according to the characteristics of different parts of the staff. These staff members are responsible for visiting the whole school, including teachers and students, visitors and so on. At the end of the semester, 6 outstanding staff members will be selected and awarded school-level certificates according to their attendance records and explanations.

\section{Conclusion}

In the future, the Science Museum will further optimize the curriculum system based on the "New Curriculum Standard" and compile excellent cases of the research-based learning program of the Xiao Xiao Science and Engineering Group. We need to continuously upgrade and update school science and technology equipment, further develop and improve school science experience library education resources, train more "little misters", establish data platform. This will strengthen the construction of the contingent of science counselors in schools, as well as the network of the Science Education Front of the 
Science Museum, the parent-child School of Xing Zhi to further enhance and maximize its function of Science Education.

\section{References:}

Ministry of Education of the People's Republic of China. (2017). Curriculum Standards of Science in elementary schools (Chinese Ed.). Beijing. Beijing Normal University Publishing Group.

Research Group on core literacy. (2016).Chinese students develop core literacy. (Chinese Ed.). Chinese Journal of Education. (10), 1-3.

Research Group of Science and Technology Museum, National Museum of Natural Science. (2015). Research Report on "Science Museum activities into campus" educational activities based on exhibits (Chinese Ed.).Research Project of "Science Museum activity into campus" of Youth Science and Technology Center of China Association for Science and Technology. 720-748.

Tao Xingzhi Education Research Association of Jiangsu Province \& Tao Xing Zhi Research Office, Xiao zhuang Normal University, Nanjing. (1981). Tao Xing Zhi Anthology (Chinese Ed.).Nanjing. Jiangsu Education Press, 362.

Wang.H \& Zhu,Y.W.(1998).The study of museums by means of information theory(Chinese Ed.). Museum research. (1), 11-16.

Wu.S.Y. (1999).A Course in the history of foreign education (Chinese Ed.). Beijing. People's Education Press, 519.

Zhu,Y.W.(2017). Exhibition Research and design from the perspective of pedagogy and communication (Chinese Ed.) The museum. (6), 71.

Zhu,Y.W.(2017). Interdisciplinary Project-based learning based on science and engineering practice (Chinese Ed.). National Museum of Natural Science (1), 5-14. 